\title{
The Pancreatic $\beta$ Cell Fraction in Children with Errors of Amino Acid Metabolism
}

\author{
R.D.G. MILNER ${ }^{(27)}$ AND P.K. WIRDNAM \\ Department of Paediatrics, University of Sheffield, Children's Hospital, Sheffield S10 2TH, England
}

\section{Summary}

Blocks of pancreas were obtained from the following cases of errors of amino acid metabolism: eight cystinosis, eight tyrosinosis, five phenylketonuria, three hypermethioninemia, two hyperprolinemia and two maple syrup urine disease. Blocks were also obtained from four cases of homocystinuria and 72 control patients of the same age range who had died from a variety of conditions believed not to affect the pancreas. Sections were cut from each pancreatic block and stained with haematoxylin or for insulin and pancreatic polypeptide (PP) by the immunoperoxidase method. Measurements were performed separately in the PP rich and the PP poor regions of all sections. The fractional surface area of section occupied by insulin stained cells $(\%)$ and the cellular density (nuclei/100 $\mu^{2}$ ) of each specimen were estimated. The $\beta$ cell fractional area in the PP poor region of the experimental cases was plotted against the logarithm of gestational age and compared to a reference grid of the 10th, 50th and 90th centile estimates of the control cases (Fig. 1). The distribution of results from the cases of tyrosinosis, phenylketonuria and cystinosis were skewed positively; four of eight tyrosinosis and three of five phenylketonuria cases lying above the 90th centile $(P<0.001)$. The $\beta$ cell fractional area of the cystinosis cases was also significantly increased (Table $1, P<0.05$ ). The results from the cases dying from maple syrup urine disease, hyperprolinemia, hypermethioninemia or homocystinuria were distributed as might be expected to occur by chance.

\section{Speculation}

The abnormal metabolic environment that occurs in some inborn errors of amino acid metabolism may lead to pancreatic $\beta$ cell hyperplasia. The increased $\beta$ cell mass found in tyrosinosis, cystinosis and phenylketonuria, if accompanied by hyperinsulinism, may be responsible for hypoglycemia.

Patients suffering from untreated inborn errors of amino acid metabolism may have a generalized or a selective hyperaminoacidemia. Tyrosinosis is not a clear cut example of an inborn metabolic error $(3,4)$ but some patients with type I tyrosinemia have been reported to exhibit hypoglycemia and, at necropsy, to have pancreatic islet hyperplasia $(4,15)$. Our interest in a systematic study of $\beta$ cell development in children dying from errors of amino acid metabolism was prompted by the anecdotal description of type I tyrosinemia, the knowledge that amino acids are insulin secretogogues (5) and the discovery that amino acids could selectively stimulate $\beta$ cell growth and insulin accumulation by embryonic rat pancreas grown in vitro $(6,11)$.

\section{MATERIALS AND METHODS}

Pancreatic specimens. Errors of amino acid metabolism are uncommon and specimens of pancreas from such patients who die and undergo necropsy are even more so. Pancreatic blocks from patients dying from errors of amino acid metabolism were col- lected by searching the archives from 1960 to 1978 of the histopathology departments of six hospitals: Birmingham Children's Hospital; Alder Hey Children's Hospital, Liverpool; Hospital for Sick Children, London; City and University Hospitals, Nottingham; Manchester Children's Hospital and the Children's Hospital, Sheffield. Blocks and limited clinical information were obtained from the following cases: eight cystinosis, eight tyrosinosis, five phenylketonuria, three hypermethioninemia, two hyperprolinemia and two maple syrup urine disease. In addition pancreatic blocks from four cases of homocystinuria were obtained from Queens University, Belfast.

The cause of death varied with diagnosis. All cases of cystinosis suffered renal failure and died with secondary renal hypertension or osteodystrophy. All of the cases of hypermethioninemia and/ or tyrosinosis had terminal hepatic failure and most died from a haemorrhagic diathesis. The causes of death of the phenylketonuric patients were: pneumonia, acute myeloblastic leukemia, meningitis and neuroblastoma. One case of hyperprolinemia died from myelofibrosis. In the other, a feverish illness led to a grand mal fit and apnoeic attacks but at necropsy no abnormality was found. Both cases of maple syrup urine disease died as a result of hypernatremic dehydration. There was necropsy information on only two of the four cases of homocystinuria. These died from bronchopneumonia and pulmonary embolus.

Control blocks of pancreas were taken from the histopathology department, Children's Hospital, Sheffield from 72 infants and children of the same age range who had died from a variety of conditions believed not to affect the pancreas and who formed part of a larger group which had been studied to define the normal development of the $\beta$ cell fraction in man (25). The region of the pancreas from which the experimental blocks had been taken had not been recorded. All specimens were therefore classified as pancreatic polypeptide (PP) rich or poor to take account of the known heterogeneity of islet cell distribution within the gland ( 1 , $2,7,9,12,13,14,17,18$ ).

Tissue processing. The varied provenance of the experimental specimens meant that little was known about tissue processing. Most were thought to have been fixed in formal saline but the death fixation interval and the fixation time were unknown. The control specimens were fixed in formal calcium for $1-2$ wk and the interval between death and fixation did not exceed $72 \mathrm{~h}$. Experimental and control specimens were dehydrated and embedded in paraffin wax in Tissue Tek cassettes (Ames Ltd). Sections $6 \mu \mathrm{m}$ thick were cut from each pancreatic block and stained for insulin or PP by the immunoperoxidase method (22). Endogenous peroxidase and erythrocyte pseudoperoxidase activity was inhibited using a methanol/hydrogen peroxide $(11: 6 \mathrm{v} / \mathrm{v})$ mixture (23). The primary antisera used were: 1:1000 guinea pig anti-porcine insulin (Miles Laboratories, Slough, England, cat. no. 65-104-1) and 1:10,000 rabbit anti-bovine pancreatic polypeptide (a gift from Dr. R. E. Chance, Eli Lilly Laboratories, Indianapolis, IN USA). The reaction period for the above antisera was $24 \mathrm{~h}$ at $4^{\circ} \mathrm{C}$. The secondary and tertiary antisera were 1:20 swine antirabbit IgG (Dako Immunoglobulins, Copenhagen, Denmark, cat. no. 21-090) and 1:100 horseradish peroxidase/rabbit anti-horse- 
radish peroxidase complex (Dako Immunoglobulins, cat. no. Z113). The reaction time for each was $40 \mathrm{~min}$ at room temperature. Sections were washed between antisera treatments with Tris saline buffer ( $\mathrm{pH} 7.6,0.05 \mathrm{M}$ ) and non-specific background staining was reduced by pretreating the sections with $1 \%$ normal swine serum in Tris saline buffer. Visualization of the peroxidase was carried out using $125 \mathrm{mg}$ of $3,4,3^{\prime}, 4^{\prime}$ tetra-amino biphenyl hydrochloride (BDH Chemicals Ltd, Poole, England, cat. no. 13033 2P) in 340 $\mathrm{ml}$ of citrate acetate buffer (pH 5.0, $0.05 \mathrm{M}$ ) containing $200 \mu \mathrm{l}$ of 100 volume hydrogen peroxide (8). Control staining was performed by preabsorbing the primary antisera with their respective antigens or by omission of the primary antisera. Both resulted in negative staining. Preabsorption of the primary antisera with antigens other than those against which they were raised did not prevent or diminish positive staining. One section from each case was also stained with haematoxylin.

Morphometric analysis. Using a Wild binocular microscope at a magnification of $\times 25$, the PP rich region of the PP stained section from each case was outlined with a mapping pen. By placing the insulin stained section on top of the PP section, the PP rich region on the former was also outlined. Measurements were performed separately in PP rich and PP poor regions of all sections.

The fractional surface area of a pancreatic section occupied by insulin stained cells was measured using an automatic image analyser (Quantimet 720). This was attached to a Nikon SKE series microscope and interfaced with a Hewlett Packard 9815A desk top calculator. The number of fields $(n)$ counted by the Quantimet was decided by performing cumulative estimates of mean and standard deviations of the $\beta$ cell fraction in the PP poor region of a postnatal pancreas to a total of 350 . The estimate of each was stable when $n$ was $>70$. One hundred consecutive fields (equivalent to $38.5 \mathrm{~mm}^{2}$ ) were therefore measured in both the PP poor and PP rich region of each pancreatic section. Large areas of interlobular connective tissue, blood vessels or processing artifacts were not included in the measurement area.

The average size of all cells in each specimen was estimated by measuring the cellular density. The number of nuclei on the haematoxylin stained section in a $40 \mu \mathrm{m}$ square were counted on a Zeiss microscope using a $\times 100$ oil immersion objective and a $\times 8$ eyepiece. By counting squares at $100 \mu \mathrm{m}$ intervals a mean cellular density (nuclei/100 $\mu^{2}$ ) was derived.

\section{RESULTS}

One case of phenylketonuria showed intense non-specific immunoperoxidase background staining which prevented further analysis. All the other 31 cases had PP poor regions and seven had PP rich regions. The $\beta$ cell fractional area (\%) in the PP poor region of the experimental cases was plotted against the logarithm of gestational age (months) and compared to a reference grid of the 10th, 50th and 90th centile estimates of the control cases (Fig. l). The results from the cases dying from maple syrup urine disease, hyperprolinemia, hypermethioninemia or homocystinuria were distributed as might be expected to occur by chance. The distribution of results from the cases of tyrosinosis, phenylketonuria and cystinosis was skewed positively; four of eight tyrosinosis and three of five phenylketonuria cases lying above the 90th centile (chi square test, $P<0.001$ ). The range of nuclear density in the tyrosinosis cases was 64-100, in phenylketonuria 66-108 and in controls $(n=68) 53-112$, thus excluding exocrine cellular shrinkage as an explanation of an apparent increase in $\beta$ cell fractional area.

In the PP rich region one case of tyrosinosis and two cases of cystinosis were above the 90 th centile. One case of tyrosinosis was below the 10th centile and the other three were between the 90th and 10 th centile lines.

The morphometric findings of the eight cases of cystinosis are presented in Table 1 where it can be seen that the nuclear density of the experimental and control tissue was similar but that the $\beta$ cell fractional area of the cystinosis cases was significantly in-

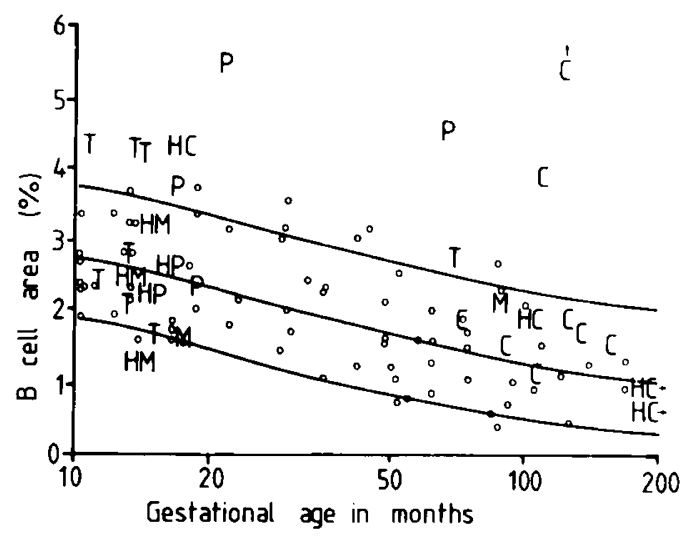

Fig. 1. Plot of pancreatic $\beta$ cell fractional area (\%) against age in months from conception (gestational age) of 72 control cases (open circles) and 31 cases of patients dying from inborn errors of amino acid metabolism ( $\mathrm{T}=$ tyrosinosis, $\mathrm{P}=$ phenylketonuria, $\mathrm{C}=$ cystinosis, $\mathrm{M}=$ maple syrup urine disease, $\mathrm{HC}=$ homocystinuria, $\mathrm{HM}=$ hypermethioninemia, $\mathrm{HP}=$ hyperprolinemia. The $10 \mathrm{th}, 50 \mathrm{th}$ and $90 \mathrm{th}$ centile lines of the control cases are shown.

Table 1. Pancreatic $\beta$ cell fractional area and pancreatic nuclear density in PP poor regions in children dying from cystinosis and in controls.

\begin{tabular}{|c|c|c|c|c|}
\hline & & $\begin{array}{l}\text { Gestational } \\
\text { age at death } \\
\text { (months) }\end{array}$ & $\begin{array}{c}\beta \text { cell } \\
\text { fractional area } \\
(\%)\end{array}$ & $\begin{array}{c}\begin{array}{c}\text { Nuclear } \\
\text { density } \\
\text { (nuclei/ } \\
100 \mu \mathrm{m}^{2} \text { ) }\end{array} \\
\end{array}$ \\
\hline \multirow{8}{*}{\multicolumn{2}{|c|}{ Cystinosis' }} & 70 & 1.88 & 32 \\
\hline & & 88 & 1.88 & 57 \\
\hline & & 101 & 1.18 & 62 \\
\hline & & 108 & 4.07 & 98 \\
\hline & & 114 & 1.84 & 73 \\
\hline & & 114 & 1.90 & 75 \\
\hline & & 119 & 11.90 & 59 \\
\hline & & 153 & 1.52 & 66 \\
\hline & mean \pm S.D. & & $3.27 \pm 3.68$ & $65 \pm 20$ \\
\hline Controls $^{2}$ & mean \pm S.D. & & $1.33 \pm 0.66$ & $73 \pm 19$ \\
\hline
\end{tabular}

${ }^{1}$ A Wilcoxon two sample rank test shows the experimental cases to have a significantly higher $\beta$ cell area than the control cases $(P<0.05)$.

${ }^{2}$ Control data are from 22 patients of gestational age 60 - 166 months described previously (25).

creased (Wilcoxon two sample rank sum test, $P<0.05$ ). The contrast between the pancreas of an 8-year-old boy who died from cystinosis and of a control patient of the same age is shown in Figure 2. The case of cystinosis shows exocrine normality and marked endocrine hyperplasia which involves particularly the $\beta$ cells.

\section{DISCUSSION}

This study has shown that there is an increased volume fraction of $\beta$ cells in the pancreas of some patients dying from tyrosinosis, phenylketonuria and cystinosis. The validity of these observations rests on a number of premises, among which the most important is the definition of normality. In a clinical study such as this, normal tissue is not available for the construction of standards. These standards were built instead by using tissue from infants and children who had died from a wide variety of causes, including both acute deaths (e.g., cot death) and deaths after long illness (e.g., neural tube defects) (25). The total control material ranged from 3-180 months gestational age and in it no significant differences in $\beta$ cell volume fraction were found when cases were subdivided by diagnosis. It was therefore considered to form a suitable matrix for the assessment of other diagnostic groups such as those considered here. The importance of a large number of 

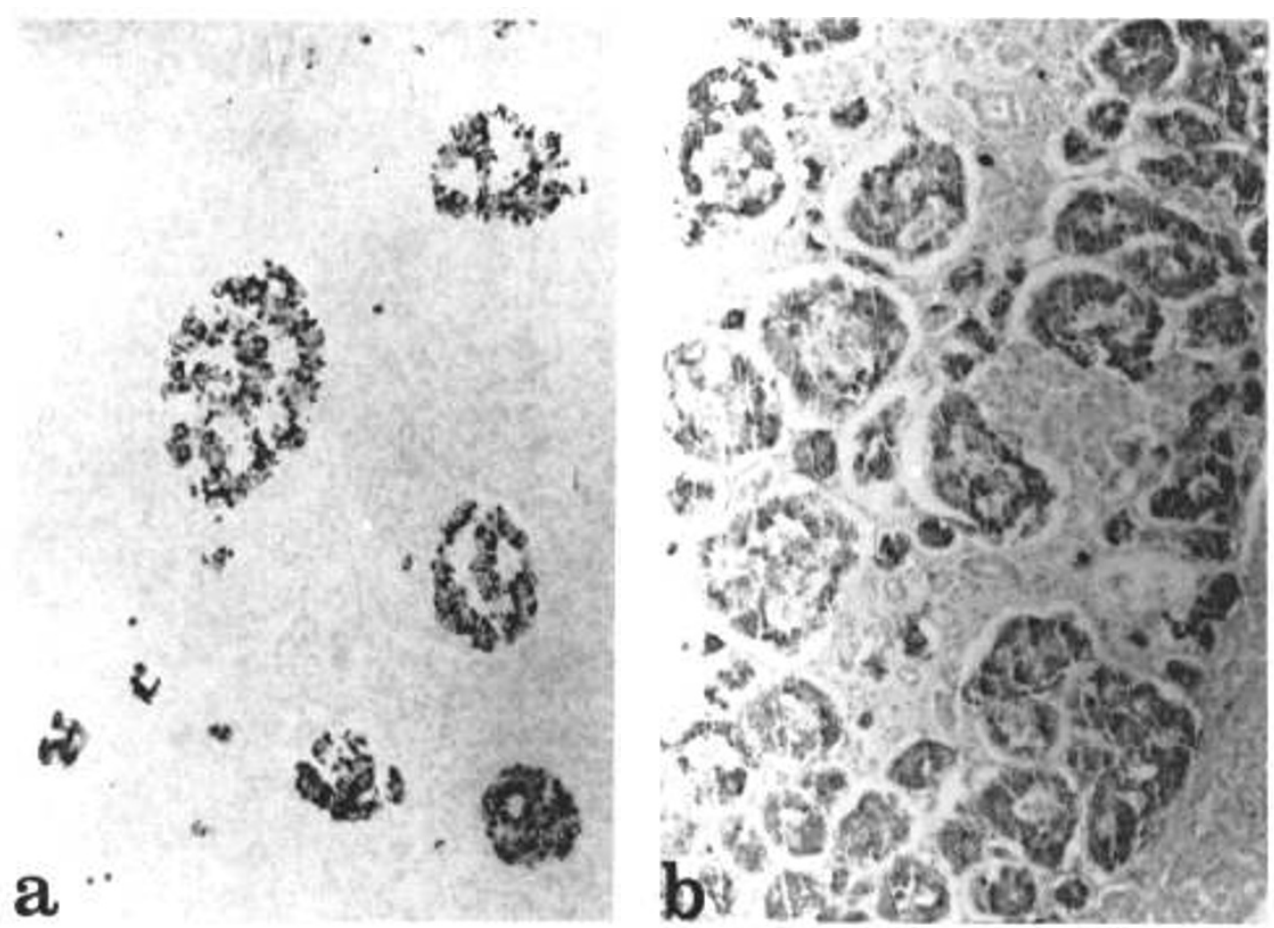

Fig. 2. Immunoperoxidase staining for insulin in the pancreas of $a$, a child of gestational age 113 months dying from meningitis and $b$, a child of gestational age 119 months dying from cystinosis. In the cystinosis case there is massive $\beta$ cell hyperplasia (original magnification $\times 40$ ).

control observations is emphasized because the range that occurs at any one age, and the fall in mean $\beta$ cell fraction and nuclear density that occurs with increasing age (25). The concentration of $\beta$ cells within the pancreas may be expressed as a volume fraction or as a function of the total number of cells in the gland $\left(\mu \mathrm{m}^{2} \beta\right.$ cells/100 nuclei.) Because no significant differences were found between the two forms of expression (24), the simpler was used here. Pancreatic nuclear density was measured in each experimental case because of the possibility that exocrine shrinkage, either from inanition or due to tissue processing, could have resulted in an artifactually high $\beta$ cell fraction. The range of nuclear density was the same, 2- to 3-fold, in both control and experimental sections and the possibility of artifact could be discounted.

Inborn errors of amino acid metabolism cover a wide spectrum of biochemical pathology and it is not surprising that a variety of results came from the seven conditions studied. The number of examples of each diagnosis was only two to eight. It is possible that were there more cases available, the conditions judged to have a normal $\beta$ cell fraction could turn out to be abnormal. It is less likely that if more examples of cystinosis, tyrosinosis and phenylketonuria had been collected these disorders would be found to have a normal $\beta$ cell fraction because each was significantly different from the control observations on the numbers studied. The distribution of results in the cystinosis cases differed from those in tyrosinosis and phenylketonuria. This may be relevant to the biochemical pathology of the three conditions. Cystinosis is thought not to result from a block in cystine metabolism but to be due to lysosomal accumulation of the amino acid (19). The $\beta$ cell fraction in the cases of cystinosis was skewed above the 50th centile. If the results had been skewed upwards but confined within the centile limits, an apparent increase of $\beta$ cell fraction due to exocrine damage might have been a plausible interpretation. Against this, the nuclear density of the cystinosis cases was the same as that of the controls. In two cases of cystinosis, the islets were grossly abnormal and would have been recognized as such subjectively (Fig. 2 ). It may be relevant that elevation of the cystine concentration in the medium used for the organ culture of embryonic rat pancreas causes a significant increase of the pancreatic insulin concentration (unpublished results). Tyrosinosis does not refer to a specific disorder of tyrosine metabolism but is a term often used empirically in patients with hypertyrosinemia $(3,4,15,16)$, some of whom have a fatal disease (Type I) and others who run a benign course (Type II). Hypertyrosinemia and hypermethioninemia are also commonly found in generalized liver disease. It is possible that the patients thus labelled who had normal $\beta$ cell fractions did not have a specific disorder of amino acid metabolism. By the same argument, those cases of tyrosinosis that had an abnormal $\beta$ cell fraction were examples of type I tyrosinemia in which islet hyperplasia has been reported previously $(4,15)$. Phenylketonuria is the classical example of a single enzyme disease $(20,21)$ and the spectrum of $\beta$ cell fraction observed could be related to the degree of clinical control of the patients. Only four cases suitable for study were obtained despite the cooperation of the U.K. national phenylketonuria registry and consultation with the doctors concerned in the 22 patients who had died from this condition in the U.K. since 1964. In most instances there was no necropsy. Where one had been performed, a pancreatic block had not been saved. As in the case of cystinosis, the endocrine pancreas of two of the four phenylketonuria cases was grossly abnormal. The two cases of maple syrup urine disease are noteworthy among the amino acid errors because leucine is known to be an insulin secretagogue (10) and chronically raised circulating levels of the branched chain amino acids might be a plausible explanation for increased $\beta$ cell development.

The morbid anatomical findings reported here may or may not have clinical relevance. There was no record of hypoglycemia in the available case notes of any of the patients with an increased $\beta$ cell fraction but these were often edited and sparse. There are anecdotal references in the literature to hypoglycemia in patients with tyrosinosis and hypermethioninemia. We hope that these observations will stimulate others to consider the possibility of abnormal endocrine pancreatic function in patients with errors of amino acid metabolism and to be diligent in their attempts to obtain pancreas for histologic examination from any who die.

\section{REFERENCES AND NOTES}

1. Baetens, D., Malaisse-Lagae, F., Perrelet, A. and Orci, L.: Endocrine pancreas: three dimensional reconstruction shows two types of islets of Langerhans Science, 206: 1323 (1979).

2. Bommer, G., Friedl, U., Heitz, P. U. and Hoppel, G.: Pancreatic PP cell distribution and hyperplasia. Virchows Arch. Path. Anat. Histol., 387: 319 (1980) 


\section{MILNER AND WIRDNAM}

3. Carson. N. A. J., Biggart. J. D., Bittles, A. D. and Donovan, D.: Hereditary tyrosinaemia: clinical, enzymatic and pathological study of an infant with the acute form of the disease. Archs. Dis. Child.. 51: 100 (1976).

4. Cohen, B. E., Keren, G., Cripsin, M., Horwitz. A., Szeinberg. A. and Legum, C.: Congenital tyrosinemia. Monogr. Hum. Genet., 9: 118 (1978).

5. Floyd, J. C.. Fajans, S. S., Conn, J. W., Knopf, R. F. and Rull, J.: Stimulation of insulin secretion by amino acids. J. Clin. Invest.. 45: 1487 (1966).

6. de Gasparo, M., Milner, G. R., Norris, P. D. and Milner, R. D. G.: Effect of glucose and amino acids on foetal rat pancreatic growth and insulin secretion in vitro. J. Endocr.. 77: 241 (1978).

7. Gersell, D. J., Gingerich, R. L. and Greider, M. H.: Regional distribution and concentration of pancreatic polypeptide in the human and canine pancreas. Diabetes, 28: 11 (1979).

8. Graham, R. C. and Karnovsky, M. J.: The early stages of absorption of injected horseradish peroxidase in the proximal tubules of the mouse kidney: ultrastructural cytochemistry by a new technique. J. Histochem. Cytochem.. 14: 291 (1966).

9. Malaisse-Lagae, F., Orci, L. and Perrelet, A.: Anatomic and hormonal markers for the ventral primordium in the human pancreas? New Engl. J. Med., 300: 436 (1979).

10. Milner, R. D. G., Ashworth, M. A. and Barson, A. J.: Insulin release from human foetal pancreas in response to glucose, leucine and arginine. J. Endocr., 52: 497 (1972).

I1. Milner, G. R., de Gasparo, M., Kay, R. and Milner, R. D. G.: Effect of glucose and amino acids on insulin, glucagon and zymogen granule size of foetal rat pancreas grown in organ culture. J. Endocr., 82: 179 (1979).

12. Orci, L., Baetens, D., Ravazzola. M., Stefan. Y. and Malaisse-Lagae, F.: Pancreatic polypeptide and glucagon: non-random distribution in pancreatic islets. Life Sci.. 19: 181! (1976)

13. Orci, L., Malaisse-Lagae, F., Baetens, D. and Perrelet, A.: Pancreatic polypeptiderich regions in the human pancreas. Lancet, 2: 1200 (1978).

14. Orci. L., Stefan, Y., Malaisse-Lagae, F. and Perrelet, A.: Instability of pancreatic endocrine cell populations throughout life. Lancet, 1: 615 (1979).

15. Perry, T. L.: Tyrosinaemia associated with hypermethioninaemia and islet cell hyperplasia. Can. Med. Ass. J., 97: 1067 (1967).

16. Perry, T. L., Hardwick, D. F., Dixon, G. H., Dolman. C. L. and Hansen, S.:
Hypermethioninemia: a metabolic disorder associated with cirrhosis, islet cell hyperplasia and renal tubular degeneration. Pediatrics, 36: 236 (1965).

17. Rahier, J., Wallon, J., Gepts, W. and Haot, J.: Localization of pancreatic polypeptide cells in a limited lobe of the human neonate pancreas: remnant of the central primordium? Cell and Tissue Res., 200: 359 (1979).

18. Rahier, J., Wallon, J. and Henquin, J. C.: Abundance of somatostatin cells in the human neonatal pancreas. Diabetologia, I8: 25I (1980).

19. Schneider, J. A., Wong, V., Bradley, K. and Seegmiller, J. E.: Biochemical comparisons of the adult and childhood forms of cystinosis. New Engl. J. Med. 279: 1253 (1968)

20. Scriver, C. R. and Clow, C. L.: Phenylketonuria: epitome of human biochemical genetics (first of two parts). New Engl. J. Med., 303: 1336 (1980).

21. Scriver, C. R. and Clow, C. L.: Phenylketonuria: epitome of human biochemical genetics (second of two parts). New Engl. J. Med., 303: 1394 (1980).

22. Sternberger, L. A., Hardy, P. H., Cuculis, J. J. and Meyer, H. G.: The unlabelled antibody enzyme method of immunohistochemistry. J. Histochem. Cytochem. 18: 315 (1970).

23. Streefkerk, J. G.: Inhibition of erythrocyte pseudoperoxidase activity by treatment with hydrogen peroxidase following methanol. J. Histochem. Cytochem.. 20: 829 (1972).

24. Wirdnam, P. K.: Development of the human endocrine pancreas. Ph.D. Thesis, University of Sheffield (1980).

25. Wirdnam, P. K. and Milner, R. D. G.: Quantitation of the B and A cell fraction in human pancreas from early fetal life to puberty. Early Human Development. 5: 299 (1981).

26. The authors are grateful to Dr. J. M. Bouton, Dr. A. H. Cameron, Dr. N. A. J. Carson, Professor A. E. Claireaux, Professor J. L. Emery, Dr. D. G. Fagan and Dr. H. B. Marsden for their generous cooperation in providing tissue for examination.

27. Requests for reprints should be addressed to: Dr. R. D. G. Milner, Department of Pediatrics, Children's Hospital. Sheffield S10 2TH, England.

28. This research was supported by the British Diabetic Association, the Wellcome Trust and the Hawley Trust.

29. Received for publication February 18, 1981.

30. Accepted for publication October 7,1981 . 